\title{
End-of-season influenza vaccine effectiveness in adults and children, United Kingdom, 2016/17
}

Richard Pebody ${ }^{1}$, Fiona Warburton 1 , Joanna Ellis ${ }^{1}$, Nick Andrews ${ }^{1}$, Alison Potts ${ }^{2}$, Simon Cottrell 3 , Arlene Reynolds ${ }^{2}$, Rory Gunson ${ }^{4}$, Catherine Thompson ${ }^{1}$, Monica Galiano ${ }^{1}$, Chris Robertson ${ }^{5}$, Naomh Gallagher ${ }^{6}$, Mary Sinnathamby ${ }^{1}$, Ivelina Yonova ${ }^{7,8}$, Ana Correa ${ }^{7}$, Catherine Moore ${ }^{3}$, Muhammad Sartaj ${ }^{6}$, Simon de Lusignan ${ }^{7,8}$, Jim McMenamin², Maria Zambon ${ }^{1}$

1. Public Health England, London, United Kingdom

2. Health Protection Scotland, Glasgow, United Kingdom

3. Public Health Wales, Cardiff, United Kingdom

4. West of Scotland Specialist Virology Centre, Glasgow, United Kingdom

5. University of Strathclyde, Glasgow, United Kingdom

6. Public Health Agency Northern Ireland, Belfast, United Kingdom

7. University of Surrey, Guildford, United Kingdom

8. Royal College of General Practitioners, London, United Kingdom

Correspondence: Richard Pebody (richard.pebody@phe.gov.uk)

Citation style for this article:

Pebody Richard, Warburton Fiona, Ellis Joanna, Andrews Nick, Potts Alison, Cottrell Simon, Reynolds Arlene, Gunson Rory, Thompson Catherine, Galiano Monica, Robertson Chris, Gallagher Naomh, Sinnathamby Mary, Yonova Ivelina, Correa Ana, Moore Catherine, Sartaj Muhammad, de Lusignan Simon, McMenamin Jim, Zambon Maria. End-of-season influenza vaccine effectiveness in adults and children, United Kingdom, 2016/17. Euro Surveill. 2017;22(44):pii=17-00306. https:// doi.org/10.2807/1560-7917.ES.2017.22.44.17-00306

Article submitted on 04 May 2017 / accepted on 15 Aug 2017 / published on 02 Nov 2017

The United Kingdom is in the fourth season of introducing a universal childhood influenza vaccine programme. The 2016/17 season saw early influenza $\mathrm{A}\left(\mathrm{H}_{3} \mathrm{~N}_{2}\right)$ virus circulation with care home outbreaks and increased excess mortality particularly in those 65 years or older. Virus characterisation data indicated emergence of genetic clusters within the $\mathrm{A}\left(\mathrm{H}_{3} \mathrm{~N}_{2}\right){ }_{3} \mathrm{C} .2 \mathrm{a}$ group which the $2016 / 17$ vaccine strain belonged to. Methods: The test-negative case-control (TNCC) design was used to estimate vaccine effectiveness (VE) against laboratory confirmed influenza in primary care. Results: Adjusted end-of-season vaccine effectiveness (aVE) estimates were $39.8 \%$ (95\% confidence interval $(\mathrm{Cl}): \mathbf{2 3 . 1}$ to 52.8$)$ against all influenza and $40.6 \%$ (95\% Cl: 19.0 to 56.3 ) in 18-64-yearolds, but no significant aVE in $\geq 65$-year-olds. aVE was $65.8 \%$ ( $95 \% \mathrm{Cl}: 30.3$ to 83.2 ) for $2-17$-year-olds receiving quadrivalent live attenuated influenza vaccine. Discussion: The findings continue to provide support for the ongoing roll-out of the paediatric vaccine programme, with a need for ongoing evaluation. The importance of effective interventions to protect the $\geq 65$-year-olds remains.

\section{Introduction}

The United Kingdom (UK) has a long-standing influenza selective immunisation programme offering inactivated vaccine to people 65 years of age and older and those 6 months to less than 65 years of age with an underlying clinical risk factor [1]. Following advice from the Joint Committee on Vaccination and Immunisation (JCVI), the UK started the incremental introduction of a universal childhood influenza vaccine programme in the 2013/14 influenza season [2] with a newly licensed intra-nasally administered live attenuated influenza vaccine (LAIV). Eligible healthy children were offered a single dose of LAIV, whereas children in a clinical risk group up to 9 years of age, with no contraindications for LAIV and not previously vaccinated, were offered two doses of vaccine. By the 2016/17 season, all children aged 2-8 years across the UK were being offered quadrivalent LAIV (LAIV4), or else quadrivalent inactivated vaccine (QIV) if LAIV4 was contraindicated [1]. In addition, Scotland and Northern Ireland offered $\mathrm{LAIV}_{4}$ also to all remaining children of primary school age up to 11 years of age. The UK has found evidence of LAIV4 effectiveness in $2015 / 16$ of $58 \%$ and continues to recommend its use [3]. This is in contrast to the United States (US) where there has been a longstanding paediatric influenza vaccination programme, and where reduced LAIV vaccine effectiveness (VE) has been described by the US Centres for Disease Control (CDC). This led to a recommendation to suspend use of LAIV in children in 2016/17 [4] and important questions about what might explain these observations of apparent reduced LAIV effectiveness, including what role prior vaccination may play [5].

The 2016/17 influenza season in the UK, as with many other northern hemisphere countries, was characterised by the early circulation of influenza $A\left(\mathrm{H}_{3} \mathrm{~N}_{2}\right)$ viruses. The season started in December 2016 and peaked over the Christmas/New Year period. It was characterised by large numbers of care home outbreaks, many of which included highly vaccinated populations, increased admissions to hospital compared with the previous season and significant excess mortality particularly among those 65 -year-old or 


\section{FIGURE 1}

Swabbing results of patients with influenza-like illness in primary care during the influenza season, United Kingdom, October 2016-March 2017

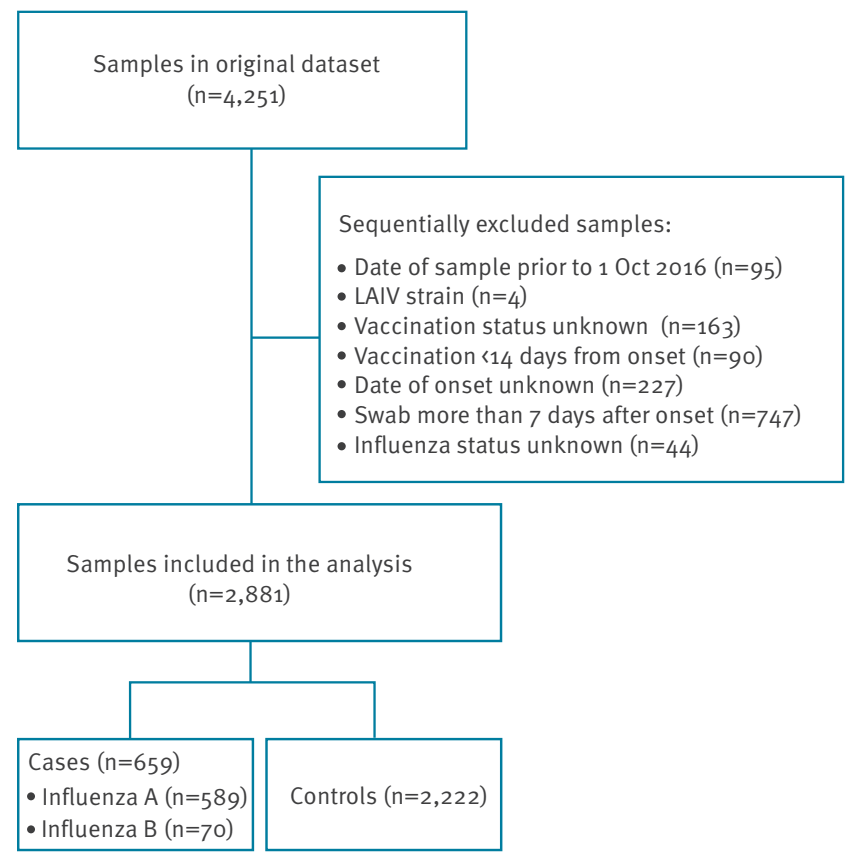

LAIV: live attenuated influenza vaccine.

older, despite vaccine uptake levels of over $70 \%$ in this age group [6]. Questions have been previously raised about the effectiveness of inactivated influenza vaccine in older persons and a range of potential explanatory factors have been postulated including what role prior vaccine exposure may play in reducing VE in this age group [7].

The UK has a well-established system to monitor influenza VE each season, including mid-season estimates based upon sentinel swabbing in primary care $[3,8]$. Here we present the 2016/17 end-of-season VE findings for laboratory-confirmed infection in primary care across all age groups, with a particular focus on LAIV 4 in children and inactivated influenza vaccine (IIV) in adult age groups and we explore the possible effect of prior season vaccination on VE in the current season. A comparison with the mid-season estimate is also undertaken.

\section{Methods}

The test-negative case-control (TNCC) design was used to estimate VE, with the study undertaken in the registered population of five sentinel general practice (GP) surveillance networks across the UK. All undertake respiratory swabbing, with details of these schemes outlined previously [3]. The schemes are: the Royal College of General Practitioners (RCGP) Research and Surveillance Centre (RSC) network, the Public Health England (PHE) Specialist Microbiology Network (SMN) and the national sentinel schemes of Wales, Scotland and Northern Ireland.

The study took place in the period from 1 October 2016, the time when influenza surveillance in primary care with respiratory swabbing was started, until 19 March 2017. A mid-season analysis was undertaken for samples taken up to 15 January 2017, in order to provide results to the annual World Health Organization (WHO) meeting on the composition of influenza virus vaccines for the next influenza season [9]. The study population comprised patients presenting to their GP during the study period with an acute influenza-like illness (ILI), who the physician consented verbally and swabbed during the consultation. The majority of the UK influenza vaccine programme is delivered in the period late September through to the end November [6].

\section{Definition of cases and controls}

A case of ILI was defined as an individual who presented with an acute respiratory illness with physiciandiagnosed fever or complaint of feverishness in the previous 7 days. Participating GPs were asked to invite persons presenting with ILI to provide a swab for diagnosis. Swabbing was undertaken regardless of vaccination status. Cases were patients who tested positive for seasonal influenza A or B virus by real-time PCR testing. Controls were patients with the same symptoms who tested negative for influenza A or B virus.

\section{Data collection}

During the consultation, the GP completed a standard questionnaire. This collected demographic (age and sex), clinical (date of onset and history of fever) and epidemiological information from patients including vaccination status and potential confounders such as underlying clinical risk factors. Vaccination status including date of vaccination was obtained mainly from patient records. Vaccine type (LAIV4 intranasal; QIV injectable) was specified on the form. Time since vaccination was stratified into 13 months and 13 months until onset of illness. Study subjects were categorised according to Department of Health defined risk categories for influenza vaccination [1]. High risk was determined by the presence of well recognised risk morbidities recorded in the electronic health record for the patient concerned. In addition, it was noted whether the general practice was in a pilot area for Englandbased paediatric immunisation schemes, where all primary school age children were offered LAIV4.

Patients were defined as vaccinated if they were reported to have received the $2016 / 17$ seasonal vaccine at least 14 days before first onset of symptoms. Patients were excluded if they were vaccinated less than 14 days before symptom onset. If date of vaccination was unknown, it was assumed to be 15 October 2016 , which was the median of all known vaccination dates this season (data not shown). 


\section{FIGURE 2}

Phylogenetic analysis of full length haemagglutinin gene comparing reference sequences from the GISAID EpiFlu database and influenza A(H3N2) sequences from patients, United Kingdom, influenza season 2016/17

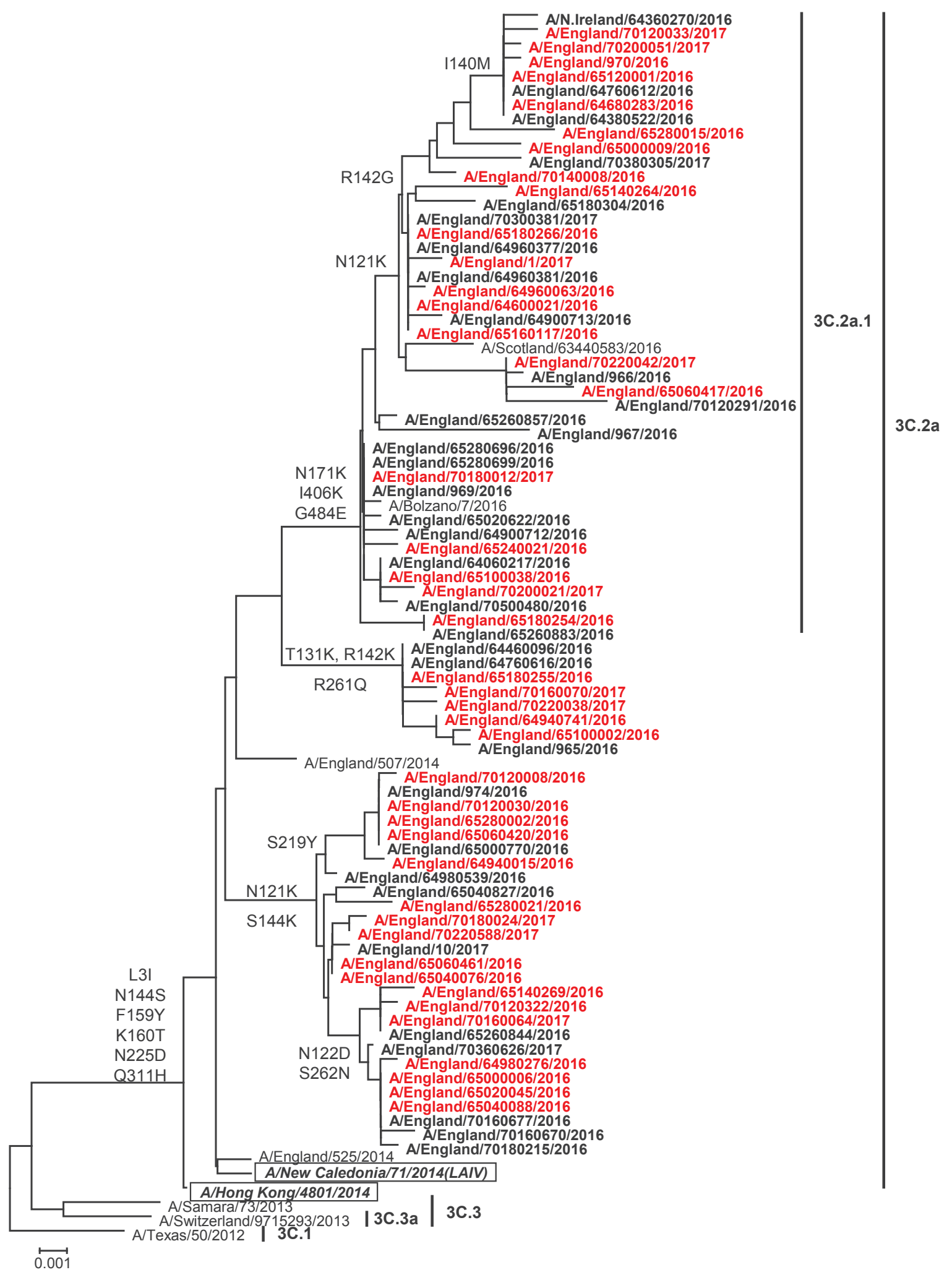

GISAID: Global Initiative on Sharing Avian Influenza Data; UK: United Kingdom.

The tree was built using a neighbour-joining algorithm, with vaccine strain A/Texas/50/2012 selected as the root. Signature amino acid substitutions characterising genetic groups are annotated at the root of each cluster. UK 2016/17 samples are highlighted in bold. Sentinel samples are highlighted in red. 


\section{FIGURE 3}

Adjusted $^{\text {a }}$ vaccine effectiveness estimates for influenza A(H3N2) by prior vaccination status and sub-type in children $2-17$ years of age ${ }^{\mathrm{b}}$ and adults $\geq 18$ years, test-negative case-control study, United Kingdom, October 2016-March 2017 ( $\mathrm{n}=659$ cases and 2,222 controls)

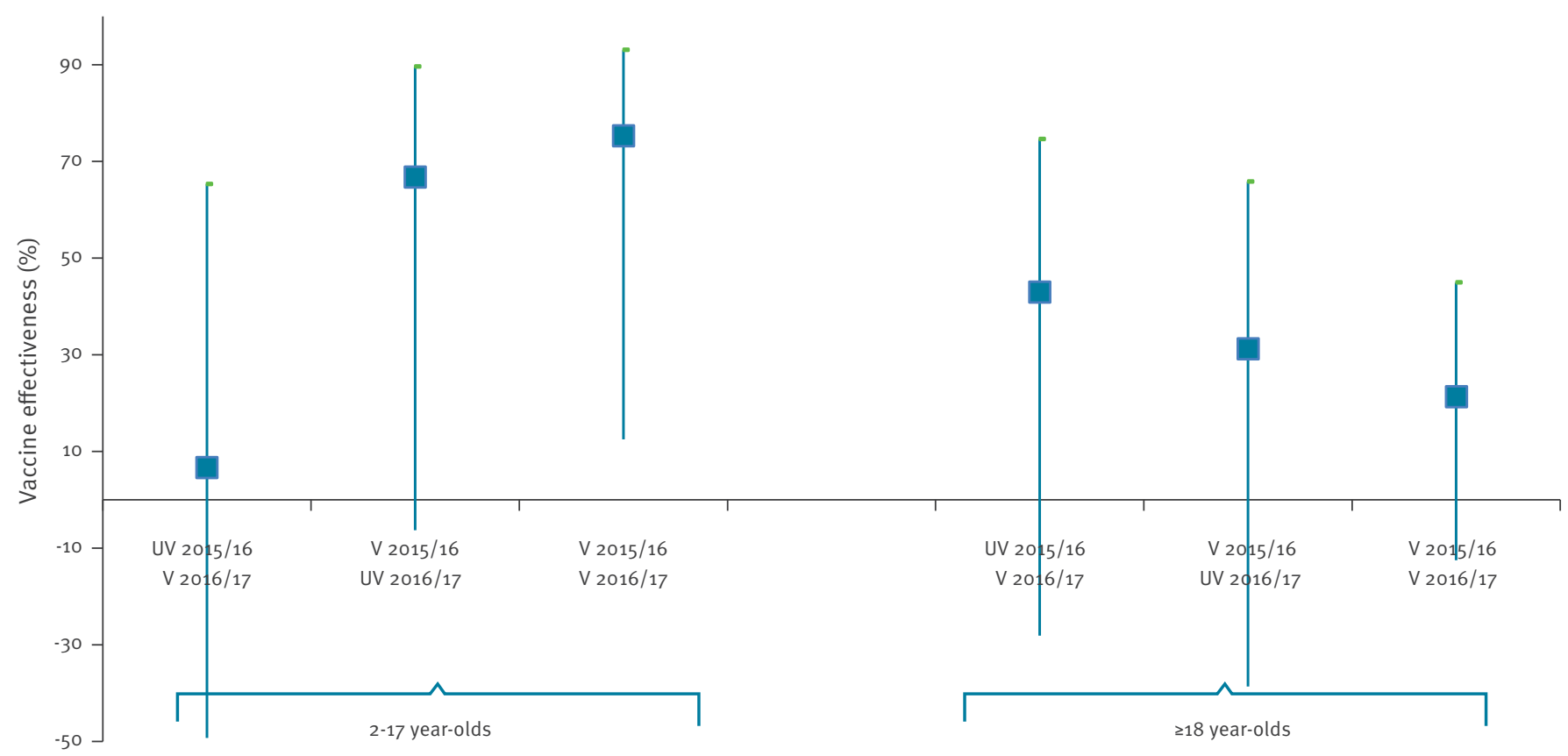

UV: unvaccinated; V: vaccinated.

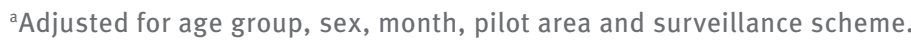

${ }^{b}$ Live attenuated influenza vaccine only.

Registered patients were excluded if they had expressed a wish to be, or the practice used one of the codes that they may not want to share data (e.g. Summary Care Record or Care.data opt-out codes).

\section{Laboratory methods}

GPs took combined throat and nose swabs which were then sent from the practice to the usual laboratory. Samples in England were sent to the PHE Reference Virus Unit, Colindale (RCGP scheme) or one of the specialist regional microbiology laboratories (SMN scheme). Samples in Wales were sent to the Public Health Wales Specialist Virology Centre and in Scotland to the West of Scotland Specialist Virology Centre (HPS scheme) (WoSPV). In Northern Ireland samples were sent to the Regional Virus Laboratory, Belfast. Influenza laboratory confirmation was made using comparable realtime PCR methods able to detect circulating influenza $A$ and influenza B viruses [10]. All laboratories then sent influenza virus-positive detections to the reference laboratories for further characterisation (RVU in London for all schemes except in Scotland where they were sent to WoSPV in Glasgow). Isolation of influenza viruses was attempted from all suitable PCR positive samples using Madin-Darby canine kidney epithelial (MDCK) cells or MDCK cells containing the cDNA of human 2,6-sialtransferase (SIAT1) cells [11,12].
Virus isolates with a haemagglutination titre $\geq 40$ were characterised antigenically using post-infection ferret antisera in haemagglutination inhibition ( $\mathrm{HI}$ ) assays, with guinea pig $\left(\mathrm{A}_{3} \mathrm{H}_{3} \mathrm{~N}_{2}\right)$ viruses) or turkey (influenza $B$ viruses) red blood cells [12]. Reference virus strains used for $\mathrm{HI}$ assays included A/HongKong/4801/2014, B/Brisbane/6o/2008, B/Phuket/3073/2013 (vaccine strains) and other $A\left(\mathrm{H}_{3} \mathrm{~N}_{2}\right)$ and influenza $B$ reference strains grown in embryonated chicken eggs and tissue culture cells.

Nucleotide sequencing of the haemagglutinin (HA) gene of a subset of influenza $A\left(\mathrm{H}_{3} \mathrm{~N}_{2}\right)$ and influenza $B$ viruses selected to be representative of the range of the patients' age, date of sample collection, geographical location and antigenic characterisation of the virus isolate, if performed, was undertaken. Phylogenetic trees of the $\mathrm{HA}$ gene of $\mathrm{A}\left(\mathrm{H}_{3} \mathrm{~N}_{2}\right)$ viruses were constructed with a neighbour-joining algorithm available in the Mega 6 software (http://www.megasoftware. net) [13].

HA sequences from reference strains used in the phylogenetic analysis were obtained from the EpiFlu database of the Global Initiative on Sharing Avian Influenza Data (GISAID) (Table 1). The HA sequences generated for this study and used in the phylogenetic analysis, 
Details of influenza A(H3N2) haemagglutinin sequences obtained from GISAID used in the phylogenetic analysis, testnegative case-control study, United Kingdom, 2016/17 influenza season

\begin{tabular}{|c|c|c|c|c|c|}
\hline Virus isolate & $\begin{array}{l}\text { Segment ID/ } \\
\text { Accession } \\
\text { number }\end{array}$ & Country & $\begin{array}{l}\text { Collection } \\
\text { date }\end{array}$ & Originating laboratory & Submitting laboratory \\
\hline A/Samara/73/2013 & $\mathrm{EPI} 460558$ & $\begin{array}{l}\text { Russian } \\
\text { Federation }\end{array}$ & 12 Mar 2013 & $\begin{array}{c}\text { WHO National } \\
\text { Influenza Centre, Saint } \\
\text { Petersburg, Russian } \\
\text { Federation }\end{array}$ & $\begin{array}{c}\text { National Institute for } \\
\text { Medical Research, London, } \\
\text { UK }\end{array}$ \\
\hline A/Switzerland/9715293/2013 & $\mathrm{EPI}_{530687}$ & Switzerland & 6 Dec 2013 & $\begin{array}{l}\text { Hopital Cantonal } \\
\text { Universitaire de } \\
\text { Geneves, Switzerland }\end{array}$ & $\begin{array}{c}\text { National Institute for } \\
\text { Medical Research, London, } \\
\text { UK }\end{array}$ \\
\hline A/Hong Kong/4801/2014 & EPI539576 & $\begin{array}{l}\text { Hong Kong } \\
\text { (SAR) }\end{array}$ & 26 Feb 2014 & $\begin{array}{l}\text { Government Virus Unit, } \\
\text { Hong Kong (SAR) }\end{array}$ & $\begin{array}{c}\text { National Institute for } \\
\text { Medical Research, London, } \\
\text { UK }\end{array}$ \\
\hline A/New Caledonia/71/2014 & $\mathrm{EPI}_{551570}$ & New Caledonia & 13 Aug 2014 & $\begin{array}{l}\text { Institut Pasteur New } \\
\text { Caledonia, New } \\
\text { Caledonia }\end{array}$ & $\begin{array}{l}\text { WHO Collaborating Centre } \\
\text { for Reference and Research } \\
\text { on Influenza, Melbourne, } \\
\text { Australia }\end{array}$ \\
\hline A/Texas/50/2012 & $\mathrm{EPI}_{556816}$ & United States & 15 Apr 2012 & $\begin{array}{c}\text { Texas Department of } \\
\text { State Health Services- } \\
\text { Laboratory Services, } \\
\text { Austin, US }\end{array}$ & $\begin{array}{c}\text { Centers for Disease Control } \\
\text { and Prevention, Atlanta, } \\
\text { US }\end{array}$ \\
\hline A/England/525/2014 & EPI611375 & UK & 20 Nov 2014 & $\begin{array}{c}\text { Microbiology Services } \\
\text { Colindale, Public } \\
\text { Health England, } \\
\text { London, UK }\end{array}$ & $\begin{array}{l}\text { Microbiology Services } \\
\text { Colindale, Public Health } \\
\text { England, London, UK }\end{array}$ \\
\hline A/England/507/2014 & EPI626573 & UK & 24 Aug 2014 & $\begin{array}{c}\text { Microbiology Services } \\
\text { Colindale, Public } \\
\text { Health England, } \\
\text { London, UK }\end{array}$ & $\begin{array}{l}\text { Microbiology Services } \\
\text { Colindale, Public Health } \\
\text { England, London, UK }\end{array}$ \\
\hline A/Bolzano/7/2016 & EPI773595 & Italy & 15 Mar 2016 & $\begin{array}{l}\text { Istituto Superiore di } \\
\text { Sanità, Rome, Italy }\end{array}$ & $\begin{array}{l}\text { Crick Worldwide Influenza } \\
\text { Centre, London, UK }\end{array}$ \\
\hline A/Scotland/63440583/2016 & EPI831436 & UK & 25 Aug 2016 & $\begin{array}{l}\text { Gart Naval General } \\
\text { Hospital, Glasgow, } \\
\text { Scotland, UK }\end{array}$ & $\begin{array}{l}\text { Microbiology Services } \\
\text { Colindale, Public Health } \\
\text { England, London, UK }\end{array}$ \\
\hline
\end{tabular}

GISAID: Global Initiative on Sharing All Influenza Data; SAR: Special Administrative Region of the People's Republic of China; UK: United Kingdom; US: United States; WHO: World Health Organization.

were deposited in GISAID's EpiFlu database under the following accession numbers: EPI913897, EPI913905, EPI913946, EPl913954, EPI913962, EPI913970, EPl913978, EPl913986, EPl913994, EPl914010, EPI914018, EPl914026, EPl914034, EPI914042, EPl914050, EPl914058, EPl914066, EPl914074, EPl914082, EPl914090, EPl914098, EPl914106, EPI914114, EPl914122, EPl914130, EPI914138, EPl914146, EPl914154, EPI914162, EPI914170, EPI914178, EPl914186, EPI914194, EPl914202, EPl914210, EPl914218, EPl914226, EPl914234, EPl914242, EPl914250, EPl914258, EPl914266, EPl914274, EPl914282, EPl914290, EPI914314, EPl914322, EPl914330, EPl914338, EPl914346, EPI914354, EPl914362, EPI914370, EPl914378, EPI914386, EPl914402, EPI914410, EPl914426, EPI914434, EPl914442, EPl914450, EPl914458, EPl914466, EPl914474, EPl914482, EPI914490, EPI914498, EPl914506, EPl914763, EPI914771, EPI914779, EPI914787, EPI914795.

\section{Statistical methods}

To analyse the swabbing results (test-negative design), the odds ratio (OR) of being vaccinated between cases and controls was used to calculate the crude VE as (1-OR) x 100\%. We performed a multivariable logistic regression, as previously $[1,8]$, to adjust VE for potential confounders with influenza laboratory results as the outcome and influenza vaccination status as the linear predictor. Estimates were calculated adjusting for age (by<2, 2-11, 12-17, 18-44, 45-64 and $\geq 65$ years), month of onset of symptoms, surveillance scheme, sex, and residence in area where a primary school programme was in place. The effect of adjustment for risk group was also assessed. Stratification was by age $2-17,18-64$ and $\geq 65$ years and was split by vaccine type (LAIV/QIV) within those aged 2-17 years. The effect of prior season vaccination was also described by calculating all the VEs i.e. for vaccinated in both $2016 / 17$ and 2015/16 seasons, vaccinated only in the $2015 / 16$ season and vaccinated only in the $2016 / 17$ season and by comparing to not vaccinated in either 
TABLE 2A

Details for influenza A and B cases and controls, test-negative influenza case-control study, United Kingdom, October 2016-March 2017 ( $n=659$ cases and 2,222 controls)

\begin{tabular}{|c|c|c|c|c|c|c|c|c|c|c|c|}
\hline \multirow[t]{2}{*}{ Characteristic } & \multicolumn{2}{|c|}{ Controls $(n=2,222)$} & \multicolumn{2}{|c|}{$\begin{array}{l}\text { Influenza B } \\
\qquad(n=70)\end{array}$} & \multicolumn{2}{|c|}{$\begin{array}{c}\text { Influenza } \\
\mathrm{A}\left(\mathrm{H}_{3} \mathrm{~N}_{2}\right)(\mathrm{n}=514)\end{array}$} & \multicolumn{2}{|c|}{$\begin{array}{l}\text { Influenza } A\left(\mathrm{H}_{1} \mathrm{~N}_{1}\right) \\
\text { pdmog }(\mathrm{n}=5)\end{array}$} & \multicolumn{2}{|c|}{$\begin{array}{c}\text { Influenza } A \\
\text { unknown }(n=70)\end{array}$} & \multirow[t]{2}{*}{$\mathrm{p}$ value } \\
\hline & $\mathrm{n}$ & $\%$ & $\mathrm{n}$ & $\%$ & $\mathrm{n}$ & $\%$ & $\mathrm{n}$ & $\%$ & $\mathrm{n}$ & $\%$ & \\
\hline \multicolumn{12}{|l|}{ Age (years) } \\
\hline$<2$ & 125 & 87.4 & 1 & 0.7 & 15 & 10.5 & 0 & 0 & 2 & 1.4 & \multirow{7}{*}{$<0.0001$} \\
\hline $2-11$ & 313 & 83.5 & 5 & 1.3 & 52 & 13.9 & 1 & 0.3 & 4 & 1.1 & \\
\hline $12-17$ & 146 & 69.9 & 9 & 4.3 & 50 & 23.9 & 0 & 0 & 4 & 1.9 & \\
\hline $18-44$ & 774 & 76.1 & 26 & 2.6 & 187 & 18.4 & 1 & 0.1 & 29 & 2.9 & \\
\hline $45-64$ & 534 & $74 \cdot 3$ & 17 & 2.4 & 140 & 19.5 & 2 & 0.3 & 26 & 3.6 & \\
\hline$\geq 65$ & 313 & 78.6 & 12 & 3 & 67 & 16.8 & 1 & 0.3 & 5 & 1.3 & \\
\hline Missing information & 17 & 85 & 0 & 0 & 3 & 15 & o & 0 & 0 & 0 & \\
\hline \multicolumn{12}{|l|}{ Sex } \\
\hline Female & 1,352 & 78.1 & 45 & 2.6 & 293 & 16.9 & 3 & 0.2 & 39 & 2.3 & \\
\hline Male & 864 & 75.7 & 25 & 2.2 & 219 & 19.2 & 2 & 0.2 & 31 & 2.7 & \\
\hline Missing & 6 & 75 & 0 & 0 & 2 & 25 & 0 & 0 & 0 & 0 & 0.144 \\
\hline \multicolumn{12}{|l|}{ Surveillance scheme } \\
\hline $\mathrm{NI}$ & 75 & 66.4 & 4 & 3.5 & 30 & 26.5 & 2 & 1.8 & 2 & 1.8 & \multirow{5}{*}{$<0.0001$} \\
\hline RCGP & 720 & 74.2 & 0 & 0 & 250 & $25 \cdot 7$ & 1 & 0.1 & 0 & 0 & \\
\hline SMN & 107 & $74 \cdot 3$ & 2 & 1.4 & 34 & 23.6 & 0 & 0 & 1 & 0.7 & \\
\hline Scotland & 1,233 & 81.7 & 62 & 4.1 & 147 & 9.7 & 1 & 0.1 & 67 & 4.4 & \\
\hline Wales & 87 & 60.8 & 2 & 1.4 & 53 & 37.1 & 1 & 0.7 & 0 & 0 & \\
\hline \multicolumn{12}{|l|}{ Risk group } \\
\hline No & 1,379 & 76.2 & 46 & 2.5 & 335 & 18.5 & 3 & 0.2 & 46 & 2.5 & \multirow{3}{*}{0.106} \\
\hline Yes & 654 & 79.1 & 18 & 2.2 & 136 & 16.4 & 2 & 0.2 & 17 & 2.1 & \\
\hline Missing & 189 & 77.1 & 6 & 2.4 & 43 & 17.6 & o & 0 & 7 & 2.9 & \\
\hline \multicolumn{12}{|c|}{ Symptom onset to swab (days) } \\
\hline $0-1$ & 262 & 75.1 & 4 & 1.1 & 76 & 21.8 & 1 & 0.3 & 6 & 1.7 & \multirow[t]{3}{*}{$<0.0001$} \\
\hline $2-4$ & 1,165 & 74.9 & 45 & 2.9 & 300 & 19.3 & 2 & 0.1 & 44 & 2.8 & \\
\hline $5-7$ & 795 & 81.5 & 21 & 2.2 & 138 & 14.1 & 2 & 0.2 & 20 & 2 & \\
\hline \multicolumn{12}{|l|}{ Vaccination status } \\
\hline Unvaccinated & 1,642 & 76.4 & 55 & 2.6 & 389 & 18.1 & 5 & 0.2 & 57 & 2.7 & \multirow{3}{*}{0.016} \\
\hline $\begin{array}{l}\text { Vaccinated (14-91 days } \\
\text { ago) }\end{array}$ & 347 & 82.4 & 5 & 1.2 & 61 & 14.5 & 0 & 0 & 8 & 1.9 & \\
\hline Vaccinated (>91 days ago) & 233 & 74.7 & 10 & 3.2 & 64 & 20.5 & o & 0 & 5 & 1.6 & \\
\hline \multicolumn{12}{|c|}{ Prior vaccination seasons ${ }^{a}$ (age group 2-17-year-olds LAIV only) } \\
\hline $\begin{array}{l}\text { Unvaccinated } 2016 / 17 \text { and } \\
2015 / 16\end{array}$ & 240 & 74.5 & 10 & 3.1 & 65 & 20.2 & 1 & 0.3 & 6 & 1.9 & \multirow{4}{*}{$<0.0001$} \\
\hline Vaccinated $2015 / 16$ only & 61 & 91 & 2 & 3 & 4 & 6 & 0 & 0 & 0 & 0 & \\
\hline Vaccinated $2016 / 17$ only & 27 & 75 & 1 & 2.8 & 8 & 22.2 & 0 & 0 & 0 & 0 & \\
\hline $\begin{array}{l}\text { Vaccinated } 2015 / 16 \text { and } \\
2016 / 17\end{array}$ & 63 & 95.5 & 0 & 0 & 3 & 4.6 & o & o & o & 0 & \\
\hline
\end{tabular}

LAIV: live attenuated influenza vaccine; NA: not applicable; NI: Northern Ireland; PHE: Public Health England; RCGP: Royal College of General Practitioners' Research and Surveillance Centre (RSC) scheme; SMN: PHE Specialist Microbiology Network.

Numbers and row percentages to indicate positivity ratesa are shown.

a Only includes those whose prior vaccination status was known. 
Details for influenza A and B cases and controls, test-negative influenza case-control study, United Kingdom, October 2016-March 2017 ( $n=659$ cases and 2,222 controls)

\begin{tabular}{|c|c|c|c|c|c|c|c|c|c|c|c|}
\hline \multirow[t]{2}{*}{ Characteristic } & \multicolumn{2}{|c|}{ Controls $(n=2,222)$} & \multicolumn{2}{|c|}{$\begin{array}{c}\text { Influenza B } \\
\qquad(\mathrm{n}=70)\end{array}$} & \multicolumn{2}{|c|}{$\begin{array}{c}\text { Influenza } \\
A\left(\mathrm{H}_{3} \mathrm{~N}_{2}\right)(\mathrm{n}=514)\end{array}$} & \multicolumn{2}{|c|}{$\begin{array}{c}\text { Influenza } A\left(\mathrm{H}_{1} \mathrm{~N}_{1}\right) \\
\text { pdmog }(\mathrm{n}=5)\end{array}$} & \multicolumn{2}{|c|}{$\begin{array}{c}\text { Influenza } A \\
\text { unknown }(n=70)\end{array}$} & \multirow[t]{2}{*}{$\mathrm{p}$ value } \\
\hline & $\mathrm{n}$ & $\%$ & $\mathrm{n}$ & $\%$ & $\mathrm{n}$ & $\%$ & $\mathrm{n}$ & $\%$ & $\mathrm{n}$ & $\%$ & \\
\hline \multicolumn{12}{|c|}{ Prior vaccination seasons ${ }^{\mathrm{a}}$ (age group 18 years and older only) } \\
\hline $\begin{array}{l}\text { Unvaccinated } 2016 / 17 \text { and } \\
2015 / 16\end{array}$ & 837 & $75 \cdot 5$ & 26 & 2.3 & 208 & 18.8 & 1 & 0.1 & 37 & $3 \cdot 3$ & \multirow{4}{*}{$<0.0001$} \\
\hline Vaccinated $2015 / 16$ only & 142 & 90.4 & 2 & 1.3 & 11 & 7 & 0 & 0 & 2 & 1.3 & \\
\hline Vaccinated $2016 / 17$ only & 50 & 76.9 & 4 & 6.2 & 8 & 12.3 & 0 & 0 & 3 & 4.6 & \\
\hline $\begin{array}{l}\text { Vaccinated } 2015 / 16 \text { and } \\
2016 / 17\end{array}$ & 351 & 79.2 & 5 & 1.1 & 79 & 17.8 & 0 & 0 & 8 & 1.8 & \\
\hline \multicolumn{12}{|c|}{ Pilot area (RCGP and SMN only) } \\
\hline No & 804 & 73.8 & 2 & 0.2 & 281 & 25.8 & 1 & 0.1 & 1 & 0.1 & \multirow[t]{2}{*}{0.092} \\
\hline Yes & 23 & 88.5 & 0 & o & 3 & 11.5 & 0 & o & 0 & o & \\
\hline \multicolumn{12}{|l|}{ Month of onset of illness } \\
\hline October & 419 & 99.3 & 0 & 0 & 3 & 0.7 & 0 & 0 & 0 & 0 & \multirow{6}{*}{$<0.0001$} \\
\hline November & 486 & 94.9 & 2 & 0.4 & 20 & 3.9 & 1 & 0.2 & 3 & 0.6 & \\
\hline December & 493 & 72.9 & 5 & 0.7 & 170 & 25.1 & 1 & 0.1 & 7 & 1 & \\
\hline January & 429 & 58.8 & 24 & $3 \cdot 3$ & 234 & 32.1 & 3 & 0.4 & 39 & 5.3 & \\
\hline February & 271 & 68.8 & 27 & 6.9 & 78 & 19.8 & 0 & 0 & 18 & 4.6 & \\
\hline March & 124 & 83.8 & 12 & 8.1 & 9 & 6.1 & 0 & 0 & 3 & 2 & \\
\hline \multicolumn{12}{|c|}{ Vaccine type (2-17-year-olds only) } \\
\hline Not Vaccinated & 344 & 75.8 & 13 & 2.9 & 89 & 19.6 & 1 & 0.2 & 7 & 1.5 & \multirow{4}{*}{ NA } \\
\hline Injection & 9 & 81.8 & 0 & 0 & 2 & 18.2 & 0 & 0 & 0 & 0 & \\
\hline Intranasal/LAIV & 101 & 89.4 & 1 & 0.9 & 11 & 9.7 & 0 & 0 & 0 & 0 & \\
\hline Missing information & 5 & 83.3 & 0 & 0 & 0 & 0 & 0 & 0 & 1 & 16.7 & \\
\hline
\end{tabular}

LAIV: live attenuated influenza vaccine; NA: not applicable; NI: Northern Ireland; PHE: Public Health England; RCGP: Royal College of General Practitioners' Research and Surveillance Centre (RSC) scheme; SMN: PHE Specialist Microbiology Network.

Numbers and row percentages to indicate positivity ratesa are shown.

a Only includes those whose prior vaccination status was known.

season. VE was calculated as $1-O R$, where $O R$ is the odds of vaccination in cases compared with controls.

End-of-season results were compared to mid-season estimates to determine the accuracy of the latter estimates.

The collection and analysis of swab forms according to positivity was undertaken as part of routine influenza surveillance, with the swabs taken to assist clinical management. The collection of the clinical data accords with routine usual practice in public health. Specific ethical approval was not necessary.

\section{Results}

During the study, 4,251 persons were sampled in the participating sentinel primary care practices and were tested. The reasons for study exclusion are summarised in Figure 1.

The details of the 2,881 individuals remaining in the study were stratified according to the swab result (Table 2) and by vaccine status (Table 3 ). There were 2,222 controls and 659 cases, of whom 589 were influenza $A\left(\mathrm{H}_{3} \mathrm{~N}_{2} \mathrm{n}=514\right.$; $\mathrm{A}$ unknown $\mathrm{n}=70 ; \mathrm{H}_{1} \mathrm{~N} 1 \mathrm{pdmo} 9$ $n=5$ ) and 70 were influenza $B$. The first positive influenza virus detection was made on 14 October 2016.

\section{Virus characterisation}

Figure 2 shows the phylogenetic analysis of the $H A$ sequences for $A\left(H_{3} N_{2}\right)$ in the $2016 / 17$ season. Genetic characterisation of $416 \mathrm{~A}\left(\mathrm{H}_{3} \mathrm{~N}_{2}\right)$ influenza viruses from all sources since week 40 showed that they all belonged to genetic subclade $3 \mathrm{C} .2 \mathrm{a}$, with 
TABLE 3

Key demographic variables by influenza vaccination status, test-negative influenza case-control study, United Kingdom, October 2016-March 2017 ( $\mathrm{n}=659$ cases and 2,222 controls)

\begin{tabular}{|c|c|c|c|c|c|}
\hline \multirow[t]{2}{*}{ Characteristic } & \multicolumn{2}{|c|}{$\begin{array}{l}\text { Not vaccinated } \\
\qquad(n=2,148)\end{array}$} & \multicolumn{2}{|c|}{$\begin{array}{l}\text { Vaccinated } \\
\qquad(n=733)\end{array}$} & \multirow[t]{2}{*}{$\mathrm{p}$ value } \\
\hline & $n$ & $\%$ & $\mathrm{n}$ & $\%$ & \\
\hline \multicolumn{6}{|c|}{ Age group (years) } \\
\hline$<2$ & 143 & 100 & 0 & 0 & \multirow{7}{*}{$<0.0001$} \\
\hline $2-11$ & 262 & 69.9 & 113 & 30.1 & \\
\hline $12-17$ & 192 & 99.5 & 1 & 0.5 & \\
\hline $18-44$ & 884 & 86.9 & 133 & 13.1 & \\
\hline $45-64$ & 521 & 72.5 & 198 & 27.5 & \\
\hline$\geq 65$ & 131 & 32.9 & 267 & 67.1 & \\
\hline Missing & 15 & 75 & 5 & 25 & \\
\hline \multicolumn{6}{|l|}{ Sex } \\
\hline Female & 1,274 & 73.6 & 458 & 26.4 & \multirow{3}{*}{0.144} \\
\hline Male & 867 & 76 & 274 & 24 & \\
\hline $\begin{array}{l}\text { Missing } \\
\text { information }\end{array}$ & 7 & 87.5 & 1 & 12.5 & \\
\hline \multicolumn{6}{|c|}{ Surveillance scheme } \\
\hline $\mathrm{NI}$ & 84 & $74 \cdot 3$ & 29 & 25.7 & \multirow{5}{*}{0.675} \\
\hline RCGP & 735 & 75.7 & 236 & 24.3 & \\
\hline SMN & 110 & 76.4 & 34 & 23.6 & \\
\hline Scotland & 1,109 & 73.4 & 401 & 26.6 & \\
\hline Wales & 110 & 76.9 & 33 & 23.1 & \\
\hline \multicolumn{6}{|l|}{ Risk group } \\
\hline No & 1,597 & 88.3 & 212 & 11.7 & \multirow{3}{*}{$<0.0001$} \\
\hline Yes & 366 & 44.3 & 461 & 55.7 & \\
\hline $\begin{array}{l}\text { Missing } \\
\text { information }\end{array}$ & 185 & $75 \cdot 5$ & 60 & 24.5 & \\
\hline \multicolumn{6}{|c|}{ Onset to swab (days) } \\
\hline $0-1$ & 271 & 77.7 & 78 & 22.3 & \multirow{3}{*}{0.305} \\
\hline $2-4$ & 1,147 & 73.7 & 409 & 26.3 & \\
\hline $5-7$ & 730 & 74.8 & 246 & 25.2 & \\
\hline \multicolumn{6}{|c|}{ Pilot area (RCGP and SMN only) } \\
\hline No & 824 & 75.7 & 265 & 24.3 & \multirow[t]{2}{*}{0.548} \\
\hline Yes & 21 & 80.8 & 5 & 19.2 & \\
\hline \multicolumn{6}{|c|}{ Month of onset of illness } \\
\hline October & 388 & 91.9 & 34 & 8.1 & \multirow{6}{*}{$<0.0001$} \\
\hline November & 393 & 76.8 & 119 & 23.2 & \\
\hline December & 469 & 69.4 & 207 & 30.6 & \\
\hline January & 510 & 70 & 219 & 30 & \\
\hline February & 276 & 70.1 & 118 & 29.9 & \\
\hline March & 112 & 75.7 & 36 & 24.3 & \\
\hline
\end{tabular}

NI: Northern Ireland; RCGP: Royal College of General Practitioners' Research and Surveillance Centre (RSC) scheme; SMN: PHE Specialist Microbiology Network

Numbers and row percentages (to indicate vaccination rates) are shown.
$220(52.9 \%)$ belonging to a cluster within this genetic subclade designated as $3 \mathrm{C} .2 \mathrm{a}$. The northern hemisphere 2016/17 influenza $A\left(\mathrm{H}_{3} \mathrm{~N}_{2}\right)$ vaccine strain $\mathrm{A} /$ HongKong/4801/2014 belongs to genetic subclade $3 \mathrm{C} .2 \mathrm{a}$ and its relatedness to the circulating strains in the 2016/17 season is shown in Figure 2. The common signature amino-acid substitutions characterising genetic groups in $3 \mathrm{C} .2 \mathrm{a}$ viruses are shown at the root of each cluster on the tree. The 2016/17 season's $\mathrm{A}\left(\mathrm{H}_{3} \mathrm{~N}_{2}\right)$ viruses were difficult to cultivate, and only 23 influenza $A\left(\mathrm{H}_{3} \mathrm{~N}_{2}\right)$ viruses were antigenically characterised since week 402016 , representing a minority of the detections and thus a potential bias in the available antigenic data. The viruses antigenically analysed were similar to the A/HongKong/4801/2014 northern hemisphere 2016/17 $\mathrm{A}\left(\mathrm{H}_{3} \mathrm{~N}_{2}\right)$ vaccine strain. Of the 23 antigenically characterised viruses, eight isolates were also genetically characterised, with all belonging to genetic group 3 C.2a, and six of them belonging to the recently emerged 3 C.2a1 cluster.

Genetic characterisation of 62 influenza B viruses from all sources was completed, with 58 (93.5\%) viruses classified as belonging to the B/Yamagata/16/88, and genetically similar to $\mathrm{B} /$ Phuket/3073/2013, the influenza B/Yamagata/16/88 component of the 2016/17 northern hemisphere quadrivalent vaccine, and four $(6.5 \%)$ classified as falling in the B/Victoria/2/87lineage and genetically similar to $\mathrm{B} /$ Brisbane/60/2008, the influenza B/Victoria/2/87 lineage component of $2016 / 17$ northern hemisphere trivalent and quadrivalent vaccines.

Eighteen influenza B viruses were isolated and antigenically characterised since week 40 2016; 13 viruses were characterised as belonging to the $B /$ Yamagata/16/88-lineage and antigenically similar to $B /$ Phuket/3073/2013, the influenza B/Yamagata-lineage component of 2016/17 northern hemisphere quadrivalent vaccine, and five (27.8\%) viruses were characterised as belonging to the $\mathrm{B} /$ Victoria/2/87-lineage and antigenically similar to $B /$ Brisbane/60/2008, the influenza B/Victoria-lineage component of 2016/17 northern hemisphere trivalent and quadrivalent vaccines.

\section{Model fitting for vaccine effectiveness estimation}

When estimating VE, age group, sex, time period (defined by month of sample collection), surveillance scheme and primary school age pilot programme area were adjusted for in a multivariable logistic regression model. All variables that were adjusted for, except for sex and primary school age pilot programme in England, were significantly associated with a positive swab (Table 2). Only month was a confounder for the vaccine effects (changing the overall estimate by more than $5 \%$ ). For any influenza (A and B), the crude VE was $14.4 \%$ (95\% Cl: $-5.0 \%$ to $30.2 \%)$, which increased to $38.2 \%$ (23.4\% to $50.2 \%)$, when month was included in the model. The crude and adjusted VE (aVE) estimates against all influenza, influenza $A\left(\mathrm{H}_{3} \mathrm{~N}_{2}\right)$ and $B$ 
TABLE 4

Influenza cases and controls according to vaccination status and VE estimates, test-negative influenza case-control study, United Kingdom, October 2016-March 2017 ( $\mathrm{n}=659$ cases and 2,222 controls)

\begin{tabular}{|l|c|c|c|c|c|}
\hline \multirow{2}{*}{ Influenza type } & \multicolumn{2}{|c|}{ Cases } & \multicolumn{2}{c|}{ Controls } & Crude VE \\
\cline { 2 - 6 } & Vaccinated & Unvaccinated & Vaccinated & Unvaccinated & Adjusted VE \\
\cline { 2 - 6 }$(95 \% \mathrm{Cl})$
\end{tabular}

$\mathrm{Cl}$ : confidence interval; VE: vaccine effectiveness.

adjusted for age group, sex, month, pilot area and surveillance scheme.

\section{TABLE 5}

Adjusted vaccine effectiveness estimates for influenza by sub-type, age group and vaccine type, test-negative case-control study, United Kingdom, October 2016-March 2017 ( $n=659$ cases and 2,222 controls)

\begin{tabular}{|c|c|c|c|c|c|c|}
\hline \multirow{2}{*}{$\begin{array}{l}\text { Influenza type/subtype and } \\
\text { age group } \\
\text { A and B }\end{array}$} & \multicolumn{2}{|c|}{ Cases } & \multicolumn{2}{|c|}{ Controls } & \multirow{2}{*}{$\begin{array}{l}\text { Crude VE } \\
(95 \% \mathrm{Cl}) \\
\end{array}$} & \multirow{2}{*}{$\begin{array}{l}\text { Adjusted }^{a} \text { VE } \\
\text { (95\% Cl) }\end{array}$} \\
\hline & Vaccinated & Unvaccinated & Vaccinated & Unvaccinated & & \\
\hline $2-17$ (IIV) & 2 & 110 & 9 & 344 & $30.5(-226.5$ to 88.6$)$ & $43.2(-183.5$ to 88.6$)$ \\
\hline 2-17 (LAIV4) & 12 & 110 & 101 & 344 & $62.8(29.8$ to 80.3$)$ & $65.8(30.3$ to 83.2$)$ \\
\hline $18-64$ & 75 & 353 & 256 & 1,052 & $12.7(-16.0$ to 34.3$)$ & $40.6(19.0$ to 56.3$)$ \\
\hline$\geq 65$ & 63 & 22 & 204 & 109 & $-53(-162.1$ to 10.7$)$ & $-6.3(-94.5$ to 42$)$ \\
\hline A & Vaccinated & Unvaccinated & Vaccinated & Unvaccinated & & \\
\hline $2-17$ (IIV) & 2 & 97 & 9 & 344 & $21.2(-270.8$ to 83.3$)$ & $30.9(-260.3$ to 86.7$)$ \\
\hline 2-17 (LAIV4) & 11 & 97 & 101 & 344 & $61.4(25.1$ to 80.1$)$ & $63.3(22.0$ to 82.7$)$ \\
\hline $18-64$ & 69 & 316 & 256 & 1,052 & $10.3(-20.4$ to 33.1$)$ & $38.5(15.1$ to 55.3$)$ \\
\hline$\geq 65$ & 55 & 18 & 204 & 109 & $-63.3(-191.8$ to 8.7$)$ & $-21.2(-134.4$ to 37.3$)$ \\
\hline $\mathrm{A}\left(\mathrm{H}_{3} \mathrm{~N}_{2}\right)$ & Vaccinated & Unvaccinated & Vaccinated & Unvaccinated & & \\
\hline $2-17$ (IIV) & 2 & 89 & 9 & 344 & $14.1(-304.6$ to 81.8$)$ & $24.9(-296.1$ to 85.8$)$ \\
\hline 2-17(LAIV4) & 11 & 89 & 101 & 344 & $57.9(18.2$ to 78.3$)$ & $57(7.7$ to 80.0$)$ \\
\hline $18-64$ & 59 & 268 & 256 & 1,052 & $9.5(-23.7$ to 33.9$)$ & $36.6(10.4$ to 55.1$)$ \\
\hline$\geq 65$ & 53 & 14 & 204 & 109 & $-102.3(-281.0$ to -7.4$)$ & $-68.4(-248.9$ to 18.7$)$ \\
\hline B & Vaccinated & Unvaccinated & Vaccinated & Unvaccinated & & \\
\hline 2-17 (LAIV4) & 1 & 13 & 101 & 344 & $73.8(-102.7$ to 96.6$)$ & $78.6(-86.0$ to 97.5$)$ \\
\hline $18-64$ & 6 & 37 & 256 & 1,052 & $33.4(-59.6$ to 72.2$)$ & $52.1(-20.0$ to 80.9$)$ \\
\hline$\geq 65$ & 8 & 4 & 204 & 109 & $-6.9(-262.9$ to 68.5$)$ & $17.2(-249.7$ to 80.4$)$ \\
\hline
\end{tabular}

$\mathrm{Cl}$ : confidence interval; IIV: inactivated influenza vaccine; LAIV4: quadrivalent live attenuated influenza vaccine; VE: vaccine effectiveness. ${ }^{\text {a }}$ Adjusted for age group, sex, month, pilot area and surveillance scheme.

are shown in Table 4. The aVE point estimate of influenza vaccine against any laboratory-confirmed infection was $39.8 \%$ (95\% Cl: 23.1 to 52.8 ) and was similar for influenza $A\left(\mathrm{H}_{3} \mathrm{~N}_{2}\right)$ at $31.6 \%(95 \% \mathrm{Cl}: 10.3$ to 47.8$)$, reflecting the fact that $\mathrm{A}\left(\mathrm{H}_{3} \mathrm{~N}_{2}\right)$ was the dominant circulating strain in the season. There were inadequate numbers of detections to enable estimation of effectiveness against influenza $\mathrm{A}\left(\mathrm{H}_{1} \mathrm{~N}_{1}\right)$ pdmog.

A secondary analysis was undertaken including risk factor in the model. This led to only small changes ( $15 \%)$ in the point estimates, but wider confidence intervals due to loss of data, with an overall aVE point estimate for all influenza of $36.8 \%$ (95\% Cl: 16.9 to 52.0 ). Further sensitivity analyses were undertaken. Firstly, including all swabs no matter how long after onset they had been taken, which made less than 3\% difference to the overall VE point estimate. Then a model including those vaccinated within 14 days as unvaccinated and including all swabs regardless of time since onset of symptoms. There was again $<3 \%$ difference to the $V E$ point estimate. 
Genetic characterisation information was available for 153 influenza $A\left(\mathrm{H}_{3} \mathrm{~N}_{2}\right)$ detections, with $663 \mathrm{C} .2 \mathrm{a}$ and 87 3C.2a1 detections giving an all age adjusted VE point estimate against 3C.2a1 of $22.7 \%(95 \% \mathrm{Cl}$ : -35.3 to 55.9$)$ and for 3 C.2a of $43.4 \%$ (95\% Cl: -12.3 to 71.5). The adjusted VE point estimate against influenza $\mathrm{B}$ was $54.5 \%(95 \% \mathrm{Cl}: 10.8$ to 76.8$)$. There were $42 \mathrm{~B} /$ Yamagata/16/88-lineage study samples with available genetic information giving an adjusted VE of $58.5 \%$ (95\% Cl: 3.1 to 82.2 ).

\section{Vaccine effectiveness against influenza A(H3N2)}

\section{In adults}

Table 5 shows the age-specific crude and aVE by subtype. The VE point estimate for inactivated vaccine (IIV) in 18-64-year-olds for influenza $\mathrm{A}\left(\mathrm{H}_{3} \mathrm{~N}_{2}\right)$ was $36.6 \%(95 \% \mathrm{Cl}: 10.4$ to 55.1 ), however, there was no significant effectiveness against influenza $A$ or specifically $\mathrm{A}\left(\mathrm{H}_{3} \mathrm{~N}_{2}\right)$ in those aged 65 years and above (aVE: $-68.4 \%$; 95\% Cl: -248.9 to 18.7 ). Although further analysis found no statistically significant decline in effectiveness by age in $\geq 18$-year-olds ( $p=0.516$ for linear trend on log-odds), the direction of the trend was towards a decrease in VE with age and this was more rapid in those aged $\geq 65$ years.

In relation to vaccination in the prior season in the $\geq 18$-year-olds (Figure 3), the VE point estimate was lowest in those vaccinated in both 2016/17 and 2015/16 seasons (21.3\%; $95 \% \mathrm{Cl}:-12.5$ to 44.9 ) and higher in those vaccinated only in the $2016 / 17$ season $(42.9 \%$; $95 \% \mathrm{Cl}:-28.1$ to 74.6$)$, although the results were not statistically significant.

\section{In children}

The crude and aVE in children 2-17 years of age for LAIV4 and IIV is shown in Table 5. The aVE point estimate for LAIV4 against influenza $A\left(\mathrm{H}_{3} \mathrm{~N}_{2}\right)$ in children 2-17 years old was $57 \%$ ( $95 \% \mathrm{Cl}: 7.7$ to 80 ), and nonsignificantly lower for IIV at $24.9 \%(95 \% \mathrm{Cl}:-296.1$ to 85.8).

Figure 3 shows the influence of $\mathrm{LAIV}_{4}$ vaccination in 2-17-year-olds in the prior season, with the VE point estimate highest in those vaccinated in both 2016/17 and $2015 / 16$ seasons ( $77.2 \%, 95 \% \mathrm{Cl}: 19.6$ to 93.5$)$ and lower in those vaccinated only in the $2016 / 17$ season (5.4\%, 95\% Cl:-140.9 to 62.8). The interaction term was significant $(p=0.029)$, with the VE for vaccinated both years being significantly different to not vaccinated in either year.

\section{Vaccine effectiveness against influenza $B$}

In adults

The age-specific VE in adults for IIV overall and stratified by age group is shown in Table 5 . In adults $18-64$ years of age, the aVE point estimate was $52.1 \%$ (95\% $\mathrm{Cl}$ : -20 to 80.9 ), whereas in those 65 years of age and above, the aVE point estimate was not statistically significant with very wide $95 \% \mathrm{Cls}$.

\section{In children}

The VE in children 2-17 years of age by vaccine type is shown in Table 5. The aVE point estimate for LAIV4 against influenza B was $78.6 \%$ (95\% Cl: -86 to 97.5$)$. There was inadequate precision to calculate VE for IIV in children. There were inadequate influenza B detections to calculate VE by prior vaccine status in either adults or children.

\section{Comparison of end-of-season to mid-season vaccine effectiveness}

The mid-season analysis comprised 1,722 individuals: 1,452 were controls and 270 cases. Of the cases, 257 were influenza A and 13 were influenza B. Mid-season VE estimates, adjusting for the same variables as the end of season analysis, provided an aVE point estimate of $26.7 \%(95 \% \mathrm{Cl}:-10.4$ to 51.3$)$ for all ages against confirmed influenza $\mathrm{A}\left(\mathrm{H}_{3} \mathrm{~N}_{2}\right)$ primary care consultation. All mid-season estimates were generally similar albeit with wider Cls compared with the end of season estimates.

\section{Discussion}

Our analysis found that in a season dominated by early circulation of influenza $A\left(\mathrm{H}_{3} \mathrm{~N}_{2}\right)$, there was moderate overall VE in preventing laboratory-confirmed influenza in primary care. Although seasonal influenza vaccine was effective against influenza $A\left(\mathrm{H}_{3} \mathrm{~N}_{2}\right)$ infection in younger adults, there was no evidence of significant effectiveness of inactivated vaccine in people aged 65 or older. On the contrary, in children there was good effectiveness for LAIV4 against influenza $A\left(\mathrm{H}_{3} \mathrm{~N}_{2}\right)$ and a suggestion of effectiveness against influenza $B$, for which there were only limited detections. Finally, we found no evidence that prior season vaccination significantly reduced the effectiveness of influenza vaccine during the current season in adults, and rather increased effectiveness in children.

There are several strengths of this study. We used the TNCC design which is a well-established approach to measure influenza VE in the UK as in many other countries. We used our standard method to provide comparability to previous seasons' UK VE estimates. The mid-season point estimates were similar to those at the end of the season, albeit with wider Cls, which is reassuring. There are, however, limitations to the study; in particular only relatively small numbers of children had received IIV with consequent broad Cls around VE point estimates and comparisons to those that have received $\mathrm{LAIV}_{4}$ should be made with caution, as the former also contained groups in whom the live vaccine was contraindicated such as those with severe asthma and immunosuppression.

The results of moderate VE in younger adults are consistent with the mid-season 2016/17 estimates published elsewhere in Europe and North America, all 
of whom experienced influenza seasons dominated by circulation of $\mathrm{A}\left(\mathrm{H}_{3} \mathrm{~N}_{2}\right)$ viruses: The Integrated Monitoring of Vaccines in Europe (I-MOVE) network reported an overall VE point estimate of $38.0 \%$ (95\% Cl: 21.3 to 51.2 ) in a number of European countries [14]; the US CDC mid-season point estimate was 43\% (95\% Cl: 29 to 54) [15] and the Canadian VE network reported a mid-season VE of $42 \%$ ( $95 \% \mathrm{Cl}: 18$ to 59 ) for all ages [16].

A small number of studies have currently reported effectiveness in those aged 65 and above for the 2016/17 season, with the I-MOVE network also reporting a non-significant VE in the $\geq 65$-year-olds of $23.4 \%$ (95\% $\mathrm{Cl}:-15.4$ to 49.1 ) [14], as did study teams from Sweden and Finland [17]. The observation of reduced VE in this vulnerable population may relate to the circulating virus strains, the vaccine itself and/or host factors. The available genetic characterisation data indicate that the circulating strains clustered to the same genetic lineages as the $2016 / 17 \mathrm{~A}\left(\mathrm{H}_{3} \mathrm{~N}_{2}\right)$ inactivated vaccine virus strain, which was an A/Hong Kong/4801/2014 $\left(\mathrm{H}_{3} \mathrm{~N}_{2}\right)$-like virus. Some authors have suggested that reduced VE may relate to the emergence of the genetic sub-clade 3C.2a1 $[17,18]$. We found a non-significantly lower VE for this sub-clade compared with the $3 \mathrm{C} .2 \mathrm{a}$ clade, although the antigenic characterisation data of circulating viruses remained limited, and there was no suggestion of mismatch based on the available information. Lower IIV VE in older adults is consistent with recent studies, which report that the current generation of inactivated vaccines against $\mathrm{A}\left(\mathrm{H}_{3} \mathrm{~N}_{2}\right)$ usually result in a lower VE in those $\geq 65$ years of age [19], where immune senescence may be an important factor. Indeed a recently published meta-analysis reported a pooled VE of $24 \%$ ( $95 \% \mathrm{Cl}:-6$ to 45$)$ in older adults for $A\left(\mathrm{H}_{3} \mathrm{~N}_{2}\right)$ [20]. Lower $V E$ in adults $\geq 65$ years of age seems to be less of an issue for $A\left(\mathrm{H}_{1} \mathrm{~N}_{1}\right)$ pdmog and influenza $B$, where generally little disease occurs in the older age groups, presumably due to underlying crossprotective immunity in this population [20].

We found no evidence of significant negative interference in adults from prior season's influenza vaccine, although VE was lower among those also vaccinated the previous season. However, the antigenic distance between the $A\left(\mathrm{H}_{3} \mathrm{~N}_{2}\right)$ viruses in the current and prior season and between the current season vaccine and current epidemic strain was only small [7].

Our findings do highlight that better vaccines for older adults are required. Adjuvanted vaccines have recently been licenced in the UK, with both them and high dose vaccines available elsewhere in Europe and North America. It will of course be important to determine the effectiveness of these vaccines; early results from the US in elderly people for high dose vaccines have been encouraging [21]. In the meantime, the VE findings for the current generation of inactivated vaccines reinforce the importance of physicians considering the added value of influenza antiviral treatment and prophylaxis for those aged 65 years and older particularly in seasons dominated by $\mathrm{A}\left(\mathrm{H}_{3} \mathrm{~N}_{2}\right)$.

This present study reports significant LAIV4 effectiveness for children 2-17 years of age against influenza $\mathrm{A}\left(\mathrm{H}_{3} \mathrm{~N}_{2}\right)$ and a high, but non-significant effectiveness against influenza $B$ albeit the numbers were low. These results continue to be reassuring, particularly in the light of the temporary suspension of $\mathrm{LAIV}_{4}$ in the US following the CDC finding of reduced VE [4]. The US results were at odds with those seen in several other countries that had used LAIV4 in 2015/16, including the UK $[5,22]$. The present study also supports results from an earlier VE study in the UK in 2014/15 that showed evidence of $\mathrm{LAIV}_{4}$ effectiveness against influenza $\mathrm{A}\left(\mathrm{H}_{3} \mathrm{~N}_{2}\right)$ compared with IIV in children, when the circulating strain was drifted from the vaccine virus strain that season. This study also found a high, but non-significant LAIV4 effectiveness against influenza B [23]. The reasons for the findings of reduced LAIV VE in the US remain unclear, though the findings were particularly notable against $\mathrm{A}\left(\mathrm{H}_{1} \mathrm{~N}_{1}\right)$ pdmog. Other countries noted relatively lower effectiveness of LAIV against $\mathrm{A}\left(\mathrm{H}_{1} \mathrm{~N}_{1}\right)$ pdmog compared with IIV in 2015/16 [24,25]. It was been suggested that this might relate to reduced replicability of the $\mathrm{A}$ (Bolivia) $\mathrm{H}_{1} \mathrm{~N}_{1}$ pdmog vaccine strain in the vaccine that year [22], though there were inadequate numbers of $A\left(\mathrm{H}_{1} \mathrm{~N}_{1}\right)$ pdmog cases this season to be able to explore this question further. Prior season vaccination has been raised as one other potential hypothesis, as the US paediatric influenza vaccine programme has been running for almost a decade compared with the more recently introduced UK programme and unlike in the UK, healthy children from 6 months to 2 years of age are offered inactivated vaccine as their priming dose. However, we found no evidence that vaccination in the prior season with $\mathrm{LAIV}_{4}$ reduced effectiveness of vaccination in the current season; a finding that matches those reported from elsewhere, such as Finland, where children could previously have received either LAIV or IIV [26]. It will, however, be critical to continue to monitor the effectiveness of LAIV in the forthcoming season, particularly with the update of the $A\left(\mathrm{H}_{1} \mathrm{~N}_{1}\right)$ pdmog vaccine virus component for the 2017/18 season to the new A/Michigan/45/2015 ( $\left.\mathrm{H}_{1} \mathrm{~N}_{1}\right)$ pdmog-like virus (A/Slovenia/2903/2015) strain and the importance of determining its effectiveness against circulating strains that season [27].

In summary, we provide encouraging results for the new UK childhood influenza vaccine programme using $\mathrm{LAIV}_{4}$, albeit in a season dominated by $\mathrm{A}\left(\mathrm{H}_{3} \mathrm{~N}_{2}\right)$ no significant effectiveness of IIV was demonstrated in adults aged 65 years and above. The level of LAIV4 effectiveness observed in 2016/17 combined with uptake in children [6] should maximise the population level benefits of the programme. These benefits are projected to provide direct protection to those vaccinated, and by reducing children's rates of infection, to indirectly protect more vulnerable members of their families and communities, in particular older adults and those who 
belong to a clinical at risk group $[28,29]$. The findings in both children and those aged 65 years and above will need further epidemiological and virological investigation. Particularly for the former age group, the results from a season dominated by circulation of influenza $A\left(\mathrm{H}_{1} \mathrm{~N}_{1}\right)$ pdmog viruses will be critically important to provide on-going assurance of the optimal design of the UK programme.

\section{Acknowledgements}

We are grateful to the many patients of participating practices who consent to virology swabs being taken; to the practices in the participating in the surveillance schemes in England, Wales, Scotland and Northern Ireland who supplied the clinical information on their patients; to the staff of the PHE Respiratory Virus Unit, the PHE Specialist Microbiology Laboratories, Public Health Wales Molecular Diagnostics Unit, the West of Scotland Specialist Virology Centre and the Regional Virus Laboratory, Belfast who undertook analysis of specimens. We thank the staff of PHE, RCGP RSC, Public Health Wales, Public Health Agency Northern Ireland and Health Protection Scotland teams who coordinate the GP schemes, in particular Praveen SebastianPillai and Nisha Oppilamany from PHE; Richard Lewis and Ember Hilvers from PHW; Cathriona Kearns, Suzanne Wilton and Chris Nugent from the PHA Catherine Frew, Alasdair MacLean and Samantha Shepherd from WoSSVC and Robert Seremani, Naoma William, Louise Primrose-Shaw, Ross Cameron and the Scottish Health Protection Network Project Team from HPS for overseeing data collection, and Filipa Ferreira, Rachel Byford, Sameera Pathirannehelage and Mariya Hriskova from RCGP RSC/University of Surrey. We acknowledge the originating and submitting laboratories of the sequences from GISAID's EpiFlu Database on which some of the analyses are based (see Table 1). All submitters of data may be contacted directly via the GISAID website www.gisaid.org.

\section{Conflict of interest}

None declared.

\section{Authors' contributions}

RP led the drafting on behalf of the group; FW and NA led on the statistical analysis; JE, RG, MG, CM and CT led on the virological analysis; all co-authors (RP, FW, JE, NA, AP, SC, AR, $R G, C T, M G, C R, N G, M S, I Y, A C, C M, M S, S L, J M, M Z$ ) contributed epidemiological and/or virological data, contributed to the design and interpretation of the results; all contributed and reviewed the early drafts and approved the final version.

\section{References}

1. Public Health England (PHE). Department of Health. Flu Plan. Winter 2016/17. London: PHE; May 2016. Available from: https://www.gov.uk/government/uploads/system/uploads/ attachment_data/file/525967/Annual_flu_plan_2016_to_2017. pdf

2. Hakin B, Cosford P, Harvey F. The flu immunisation programme 2013/14- extension to children. London: Department of Health; 26 Jul 2013. Available from: https://www.gov.uk/government/ uploads/system/uploads/attachment_data/file/225360/ Children s flu letter_2013.pdf</eref>

3. Pebody R, Warburton F, Ellis J, Andrews N, Potts A, Cottrell S, et al. Effectiveness of seasonal influenza vaccine for adults and children in preventing laboratory-confirmed influenza in primary care in the United Kingdom: 2015/16 end-of-season results. Euro Surveill. 2016;21(38):30348. https://doi. org/10.2807/1560-7917.ES.2016.21.38.30348 PMID: 27684603

4. Grohskopf LA, Sokolow LZ, Broder KR, Olsen SJ, Karron RA, Jernigan DB, et al. Prevention and Control of Seasonal Influenza with Vaccines. MMWR Recomm Rep. 2016;65(5):1-54. https://doi.org/10.15585/mmwr.rr6505a1 PMID: 27560619

5. Penttinen PM, Friede MH. Decreased effectiveness of the influenza $A\left(\mathrm{H}_{1} \mathrm{~N}_{1}\right)$ pdmog strain in live attenuated influenza vaccines: an observational bias or a technical challenge? Euro Surveill. 2016;21(38):30350. https://doi.org/10.2807/15607917.ES.2016.21.38.30350 PMID: 27684999

6. Public Health England (PHE).Weekly National Flu Report. London: PHE; 19 Jan 2017. Available from: https://www. gov.uk/government/uploads/system/uploads/attachment_ data/file/584583/Weekly national influenza_report week_03_2017.pdf

7. Skowronski DM, Chambers C, De Serres G, Sabaiduc S, Winter $A L$, Dickinson JA, et al. Serial vaccination and the antigenic distance hypothesis: effects on influenza vaccine effectiveness during $A\left(\mathrm{H}_{3} \mathrm{~N}_{2}\right)$ epidemics in Canada, 2010-11 to 2014-15. J Infect Dis. 2017;215(7):1059-99. https://doi.org/10.1093/ infdis/jix074 PMID: 28180277

8. Fleming DM, Andrews NJ, Ellis JS, Bermingham A, Sebastianpillai P, Elliot AJ, et al. Estimating influenza vaccine effectiveness using routinely collected laboratory data. Epidemiol Community Health. 2010;64(12):1062-7. https://doi. org/10.1136/jech.2009.093450 PMID: 19910645

9. World Health Organization (WHO). WHO Consultation and Information Meeting on the Composition of Influenza Virus Vaccines for Use in the 2017-2018 Northern Hemisphere Influenza Season. Geneva: WHO; 20 Dec 2016. Available from: http://www.who.int/influenza/vaccines/virus/ recommendations/consultation201702/en/

10. Gunson R, Maclean A, Davies E, Bennett S, Miller R, Carman WF. Development of a multiplex real-time RT-PCR that allows universal detection of influenza $A$ viruses and simultaneous typing of influenza $A / \mathrm{H}_{1} \mathrm{~N}_{1} / 2009$ virus. J Virol Methods. 2010;163(2):258-61. https://doi.org/10.1016/j. jviromet.2009.10.006 PMID: 19854220

11. Matrosovich M, Matrosovich T, Carr J, Roberts NA, Klenk HD. Overexpression of the alpha-2,6-sialyltransferase in MDCK cells increases influenza virus sensitivity to neuraminidase inhibitors. J Virol. 2003;77(15):8418-25. https://doi. org/10.1128/JVI.77.15.8418-8425.2003 PMID: 12857911

12. Zambon M. Laboratory Diagnosis of Influenza. In: Nicholson K, Hay A, Webster RG, editors. Textbook of Influenza. Oxford: Blackwell Science; 1998. pp. 291-313.〈/edb>

13. Tamura K, Stecher G, Peterson D, Filipski A, Kumar S. MEGA6: Molecular Evolutionary Genetics Analysis version 6.0. Mol Biol Evol. 2013;30(12):2725-9. https://doi.org/10.1093/molbev/ mst197 PMID: 24132122

14. Kissling E, Rondy MI-MOVE/I-MOVE+ study team. Early 2016/17 vaccine effectiveness estimates against influenza $A\left(\mathrm{H}_{3} \mathrm{~N}_{2}\right)$ : I-MOVE multicentre case control studies at primary care and hospital levels in Europe. Euro Surveill. 2017;22(7):30464. https://doi.org/10.2807/1560-7917.ES.2017.22.7.30464 PMID: 28230524

15. Flannery B, Chung JR, Thaker SN, Monto AS, Martin ET, Belongia EA, et al. Interim Estimates of 2016-17 Seasonal Influenza Vaccine Effectiveness - United States, February 2017. MMWR Morb Mortal Wkly Rep. 2017;66(6):167-71. https://doi. org/10.15585/mmwr.mm6606a3 PMID: 28207689

16. Skowronski DM, Chambers C, Sabaiduc S, Dickinson JA, Winter AL, De Serres G, et al. Interim estimates of 2016/17 vaccine effectiveness against influenza $A\left(\mathrm{H}_{3} \mathrm{~N}_{2}\right)$, Canada, January 2017. Euro Surveill. 2017;22(6):30460. https://doi. org/10.2807/1560-7917.ES.2017.22.6.30460 PMID: 28205503

17. Hergens MP, Baum U, Brytting M, Ikonen N, Haveri A, Wiman $\AA$, et al. Mid-season real-time estimates of seasonal influenza vaccine effectiveness in persons 65 years and older in registerbased surveillance, Stockholm County, Sweden, and Finland, January 2017. Euro Surveill. 2017;22(8):30469. https://doi. org/10.2807/1560-7917.ES.2017.22.8.30469 PMID: 28251891

18. Skowronski DM, Chambers C, Sabaiduc S, Dickinson IA, Winter AL, De Serres G, et al. Interim estimates of 2016/17 vaccine effectiveness against influenza $A\left(\mathrm{H}_{3} \mathrm{~N}_{2}\right)$, Canada, January 2017. Euro Surveill. 2017;22(6):30460. https://doi. org/10.2807/1560-7917.ES.2017.22.6.30460 PMID: 28205503

19. McLean HQ, Thompson MG, Sundaram ME, Kieke BA, Gaglani $M$, Murthy K, et al. Influenza vaccine effectiveness in the United States during 2012-2013: variable protection by age and virus type. J Infect Dis. 2015;211(10):1529-40. https://doi. org/10.1093/infdis/jiu647 PMID: 25406334

20. Belongia EA, Simpson MD, King JP, Sundaram ME, Kelley NS, Osterholm MT, et al. Variable influenza vaccine effectiveness by subtype: a systematic review and meta-analysis of 
test-negative design studies. Lancet Infect Dis. 2016;16(8):94251. https://doi.org/10.1016/S1473-3099(16)00129-8 PMID: 27061888

21. Shay DK, Chillarige Y, Kelman J, Forshee RA, Foppa IM, Wernecke $M$, et al. Comparative Effectiveness of High-Dose Versus Standard-Dose Influenza Vaccines Among US Medicare Beneficiaries in Preventing Postinfluenza Deaths During 20122013 and 2013-2014. J Infect Dis. 2017;215(4):510-7. https:// doi.org/10.1093/infdis/jiw641 PMID: 28329311

22. Ambrose CS, Bright $\mathrm{H}$, Mallory R. Letter to the editor: Potential causes of the decreased effectiveness of the influenza $A\left(\mathrm{H}_{1} \mathrm{~N}_{1}\right)$ pdmog strain in live attenuated influenza vaccines. Euro Surveill. 2016;21(45):30394. http://dx.doi.org/ https://doi. org/10.2807/1560-7917.ES.2016.21.45.30394 PMID:27918259</ jrn>

23. Pebody RG, Green HK, Andrews N, Boddington NL, Zhao H, Yonova I, et al. Uptake and impact of vaccinating school age children against influenza during a season with circulation of drifted influenza A and B strains, England, 2014/15. Euro Surveill. 2015;20(39):30029. https://doi.org/10.2807/15607917.ES.2015.20.39.30029 PMID: 26537222

24. Caspard H, Mallory RM, Yu J, Ambrose CS. Live-Attenuated Influenza Vaccine Effectiveness in Children From 2009 to 20152016: A Systematic Review and Meta-Analysis. Open Forum Infect Dis. 2017;4(3):ofx111. https://doi.org/10.1093/ofid/ ofx111 PMID: 28852675

25. Pebody R, McMenamin J, Nohynek H. Live attenuated influenza vaccine (LAIV): recent effectiveness results from the USA and implications for LAIV programmes elsewhere. Arch Dis Child. 2017 Aug 30. pii: archdischild-2016-312165. doi: https://doi. org/10.1136/archdischild-2016-312165

26. Nohynek H, Baum U, Syriänen R, Ikonen N, Sundman J, Jokinen J. Effectiveness of the live attenuated and the inactivated influenza vaccine in two-year-olds - a nationwide cohort study Finland, influenza season 2015/16. Euro Surveill. 2016;21(38):30346. https://doi.org/10.2807/1560-7917. ES.2016.21.38.30346 PMID: 27684447

27. World Health Organization (WHO). Recommended composition of influenza virus vaccines for use in the 2017-2018 northern hemisphere influenza season. Geneva: WHO; 2 Mar 2017. Available from: http://www.who.int/influenza/vaccines/virus/ recommendations/2017_18_north/en/

28. Hodgson D, Baguelin M, Leeuwen E, Panovska-Griffiths J, Ramsay M, Pebody R, Atkins KE. Effect of mass paediatric infl uenza vaccination on existing infl uenza vaccination programmes in England and Wales: a modelling and costeffectiveness analysis. Lancet Public Health Published Online January 10, 2017. http://dx.doi.org/ https://doi.org/10.1016/ S2468-2667(16)30044-5 .

29. Loeb M, Russell ML, Manning V, Fonseca K, Earn DJ, Horsman $\mathrm{G}$, et al. Live Attenuated Versus Inactivated Influenza Vaccine in Hutterite Children: A Cluster Randomized Blinded Trial. Ann Intern Med. 2016;165(9):617-24. https://doi.org/10.7326/M160513 PMID: 27538259

\section{License and copyright}

This is an open-access article distributed under the terms of the Creative Commons Attribution (CC BY 4.0) Licence. You may share and adapt the material, but must give appropriate credit to the source, provide a link to the licence, and indicate if changes were made.

This article is copyright of the authors, 2017. 